\title{
Prospective study of early rheumatoid arthritis. II. Association of rheumatoid factor isotypes with fluctuations in disease activity
}

\author{
R. H. WITHRINGTON ${ }^{1}$ INGVAR TEITSSON,${ }^{2}$ HELGI VALDIMARSSON ${ }^{3}$ AND \\ M. H. SEIFER T
}

From the ${ }^{1}$ Department of Rheumatology, St Mary's Hospital and ${ }^{2}$ Department of Immunology, St Mary's Hospital Medical School, London W2, UK, and ${ }^{3}$ Department of Immunology, the National University Hospital, 101 Reykjavik, Iceland

SUMMARY Thirty-three patients with early peripheral synovitis were followed up for two to four years in order to study the relationship between fluctuations in rheumatoid factor (RF) levels and indices of clinical activity. Twenty-eight of these patients developed classical/definite rheumatoid arthritis (RA). Seventeen patients developed erosive disease of their hands and wrists and thirteen had a positive RF agglutination test. Nineteen patients had raised levels of IgM, RF, $\operatorname{IgA}, \mathrm{RF}$, or IgG RF as measured by isotype-specific ELISA techniques. The within-patient fluctuations in IgA RF levels correlated significantly with the corresponding fluctuations in grip strength $(\mathrm{p}<0.05)$, erythrocyte sedimentation rate $(E S R)(p<0.01)$, and a composite index of disease activity $(p<0.02)$. IgG RF levels were also associated with changes in ESR and grip strength, but IgM RF showed only a weak association with fluctuations in ESR and not with any other clinical parameters. It is suggested that serum IgA RF may be a useful marker of disease activity in rheumatoid arthritis.

Rheumatoid factors (RF) of the agglutinating type occur in over $75 \%$ of rheumatoid arthritis (RA) patients, ${ }^{1}$ and intracellular IgG RF complexes have been reported to be particularly prominent in synovial tissues from seronegative RA patients. ${ }^{2}$ Thus, RFs are an immunological hallmark of RA and may be directly involved in the pathogenesis. ${ }^{34}$ There is considerable uncertainty, however, as to the relationship between rheumatoid factors and clinical disease activity. Otten and Boerma ${ }^{5}$ found no close association between levels of agglutinating RF and disease activity and most authors are in agreement. Agglutinating RFs are predominantly of the IgM isotype but IgG RF and IgA RF are also known to occur, ${ }^{67}$ and recent progress in solid phase immunoassay techniques has enabled the development of isotype-specific RF assays. ${ }^{89}$

The aim of this prospective study on early RA was to define more closely the relationship between

Accepted for publication 10 May 1984.

Correspondence to Dr M. H. Seifert, Department of Rheumatology, St Mary's Hospital, London W2 1NY. fluctuations in levels of individual RF isotypes and clinical indices of disease activity. The results indicate that serum IgA RF levels reflect fluctuations in disease activity more closely than the levels of IgG RF or IgM RF. A strong relationship between an early rise in IgA RF and the subsequent development of erosions was also noted and is reported in a separate publication. ${ }^{10}$

\section{Materials and methods}

PATIENTS STUDIED

The patients presented in this paper are part of an ongoing prospective study which was started in early 1979. Patients were admitted to the study if, on referral to the Rheumatology Outpatient Department, they had active peripheral synovitis suggestive of RA of less than one year's duration. Those who had already been treated with gold, penicillamine, corticosteroids, or cytotoxic drugs were excluded. Patients with evidence of gout, ankylosing spondylitis, Reiter's disease, psoriatic arthritis, or colitic arthropathy were also excluded. 
FOLLOW-UP, ASSESSMENT PROTOCOL

The patients were followed up in a special outpatient clinic which was held at the same time of day throughout the study. They were assessed every three months according to a protocol, and seen more frequently if necessary because of therapy. The same physician (R.H.W.) performed all the clinical assessments. If, after a minimum of two-year follow-up, the patient was asymptomatic, the interval between assessments was sometimes extended to six months.

The protocol included the following:

(a) Duration in minutes of early morning stiffness (EMS).

(b) Global pain where the patient marked the severity of his/her overall pain on a $10 \mathrm{~cm}$ long horizontal visual analogue scale (PVAS).

(c) Overall joint tenderness, expressed as the Ritchie articular index (RAI), by the method of Ritchie et al. ${ }^{11}$

(d) Grip strength (GS), measured by a specially designed grip bag ${ }^{12}$ inflated to $30 \mathrm{mmHg}$. The results were expressed as the mean of six readings, three for each hand.

(e) Blood was drawn at each assessment for estimation of erythrocyte sedimentation rate (ESR) and RF levels by both conventional agglutination tests (RAHA and latex) and isotype-specific ELISA. ${ }^{13}$ Those patients whose serum was RAHA positive (titre $\geq 1 / 40$ ) at least once were considered to meet the 8th ARA criterion for seropositivity. ${ }^{14}$

DATA ANALYSIS

The overall index of disease activity (IDA) was calculated for each visit. The EMS, PVAS, RAI, GS, and ESR were each assigned a grade of $1-4$ by means of the table of Mallya and Mace, ${ }^{15}$ where grade 1 indicates normal state and grade 4 extreme affection by disease. The mean of the five constituted the IDA (range 1.0-4.0).

The results of the ELISA tests for IgM RF, IgA $\mathrm{RF}$, and IgG RF were expressed as units/ml as described previously. $^{10}$ The clinical/serological follow-up data for each patient were analysed separately by Spearman's rank correlation method. The coefficients $\left(r_{s}\right)$ for the interparameter correlations were calculated by a BMDP statistical package (University of California, Los Angeles, USA). Subsequently, the distribution of the coefficients was normalised by dividing each coefficient by its approximate standard deviation: $1 / \sqrt{n-1}$, where $n$ was the number of clinical assessments for each patient. ${ }^{16}$ The association between the individual parameters in the group of 33 was then assessed by testing the hypothesis that the mean of $r_{s} \sqrt{n-1}$ for any two parameters was not different from zero. Student's $t$ test was used for this purpose.

\section{Results}

THE PATIENTS STUDIED: CLINICAL FEATURES AND TREATMENT

Forty-six patients entered the study. Of these, 33 were followed up for a minimum of 24 months from the onset of their symptoms. Of the remaining 13 , who did not complete a two-year follow-up, two died (one from lung cancer, the other from myocardial infarction), three moved out of the UK, and eight were lost to follow-up. Six of these eight had no joint symptoms when last seen. Unless otherwise stated, the following analysis is based exclusively on the 33 patients, followed for two years or more.

Table 1 shows the age and sex distribution of the group. There were 21 females and 12 males, a female/male ratio of $1 \cdot 8$. The mean age at the onset of symptoms was 52.9 years, age range $22-80$ years. Twenty-eight patients met five or more of the ARA criteria for $\mathrm{RA}^{14}$ at some stage during the follow-up. These were classified as RA (classical/definite) and the remaining five as non-RA (Table 1).

Seventeen of the 28 RA patients $(61 \%)$ developed erosive disease of their hands and wrists during the follow-up (Table 1). The time from the onset of symptoms until the date of the last $x$-ray ranged from 24 to 48 months. However, there was no significant correlation between the duration of disease and the number of erosions in the RA group ( $p>0.05, r=0.37$, Pearson's product-moment correlation method).

Table 1 Summary of clinical features and drug requirements of the group of 33 who were followed up for at least two years

\begin{tabular}{lll}
\hline & $R A$ & non-RA \\
\hline Total number & 28 & 5 \\
Females/males & $19 / 9$ & $2 / 3$ \\
Mean age at onset \pm 1 SD & $55 \cdot 9 \pm 16 \cdot 5 \mathrm{yr}$ & $35 \cdot 8 \pm 9 \cdot 3 \mathrm{yr}$ \\
Age range at onset & $22-80 \mathrm{yr}$ & $26-51 \mathrm{yr}$ \\
No. of ARA criteria for RA: 4 & - & 5 \\
No. of ARA criteria for RA: 5 & 7 & - \\
No. of ARA criteria for RA: 6 & 13 & - \\
No. of ARA criteria for RA: 7 & 8 & - \\
Erosive disease (hands and wrists) & $17(61 \%)$ & 0 \\
Treated with: steroids (S) & $14(50 \%)$ & 0 \\
Treated with: gold (G) & $8(29 \%)$ & 0 \\
Treated with: penicillamine (P) & $6(21 \%)$ & 0 \\
Treated with: azathioprine (A) & $1(4 \%)$ & 0 \\
Treated with: G/P/A & $8(29 \%)$ & 0 \\
Treated with: S/G/P/A & $14(50 \%)$ & 0 \\
\hline
\end{tabular}


Eight of the RA patients required gold (sodium aurothiomalate) treatment, and Table 1 shows that six of these eight also required penicillamine and one azathioprine during the follow-up. All these eight and six other RA patients, $50 \%$ of the RA group, were treated with oral steroids (low dose prednisolone) at some stage during the follow up. The decision to treat with the 'specific' drugs or steroids was based on conventional criteria, such as persistent synovitis with disabling symptoms despite full treatment with non-steroidal anti-inflammatory drugs and progression of bone erosions on $x$-ray.

\section{RHEUMATOID FACTOR PROFILES}

Thirteen of the group of $33(39 \%)$ were seropositive (titre $>1 / 40$ ) on one or more occasion in the RAHA agglutination test for $\mathrm{RF}^{17}$ and thus met the 8th ARA criterion for seropositivity. All these 13 developed classical/definite RA, and the frequency of seropositivity in the RA group was therefore $46 \%$.

A total of 651 serum and synovial fluid samples were collected from the patients of the study and assayed by ELISA for IgM RF, IgA RF, and IgG $\mathrm{RF}$ as described elsewhere. ${ }^{10}$ "With the results expressed as net absorbance, the IgA RF levels showed an overall highly significant association with IgM RF $(r=0.676, n=651, p<0.001$, Pearson's product-moment correlation method). Furthermore, the IgM RF levels showed a significant overall correlation with IgG RF $(r=0 \cdot 407, n=643$, $\mathrm{p}<0.001$, Pearson's product-moment correlation method).

Raised levels of IgM RF, IgA RF, or IgG RF as measured by ELISA were observed at some stage in $19(58 \%)$ of the group of 33 . When the five non-RA patients were excluded, $18 / 28(64 \%)$ developed raised $\mathrm{RF}$ at some stage. Table 2 shows the frequency of raised individual RF isotypes as measured by ELISA at the first visit, $4.7 \pm 3.0$ months (mean $\pm 1 \mathrm{SD}$ ) after the onset of symptoms. Seven

Table 2 The frequency of raised $R F$ levels in the prospective study group of 33 , both at onset and during the follow-up

\begin{tabular}{llcc}
\hline & $\begin{array}{l}\text { Upper limit } \\
\text { of normal* }\end{array}$ & $\begin{array}{l}\text { No. with } \\
\text { raised levels } \\
\text { at onset }\end{array}$ & $\begin{array}{l}\text { No. with } \\
\text { raised levels } \\
\text { at onset } \\
\text { or later }\end{array}$ \\
\hline IgA RF & $<10 \mathrm{U} / \mathrm{ml}$ & $7(21 \%)$ & $9(27 \%)$ \\
IgM RF & $\leq 20 \mathrm{IU} / \mathrm{ml}$ & $10(30 \%)$ & $13(39 \%)$ \\
IgG RF & $<80 \mathrm{U} / \mathrm{ml}$ & $4(12 \%)$ & $8(24 \%)$ \\
\hline
\end{tabular}

${ }^{*}$ Levels above the $95 \%$ upper limits for 102 normals, $\geq 10 \mathrm{U} / \mathrm{ml}$, $>20 \mathrm{IU} / \mathrm{ml}$ and $\geq 80 \mathrm{U} / \mathrm{ml}$ for IgA RF, IgM RF and IgG RF, respectively, were taken as raised.
$(21 \%)$ and ten $(30 \%)$ patients presented with raised IgA RF and IgM RF, respectively. After admission to the study only two patients developed raised $\operatorname{IgA}$ $\mathrm{RF}$ and three raised IgM RF.

Few extra-articular manifestations were seen in this group. One woman with persistent high serum level of IgA RF developed Felty's syndrome. ${ }^{18}$ Rheumatoid nodules were seen in only one patient who had raised IgM RF and IgA RF but normal IgG RF. One seronegative patient developed Sjögren's syndrome.

\section{INTERRELATIONS OF CLINICAL AND}

SEROLOGICAL PARAMETERS

The follow-up profiles of EMS, PVAS, GS, ESR, IDA, IgM RF, IgA RF, IgG RF were intercorrelated for each of the 33 patients separately by Spearman's rank correlation method. The number of assessments for each patient upon which the analysis was based varied from 5 to 12 , mean $7 \cdot 6$. As an example, Fig. 1 shows the follow-up profiles of IDA, IgM RF, IgA RF, and IgG RF for a patient who developed classical RA. The rank correlation coefficients $\left(r_{s}\right)$ for the association between the RF isotypes and the IDA are also shown in Fig. 1. The

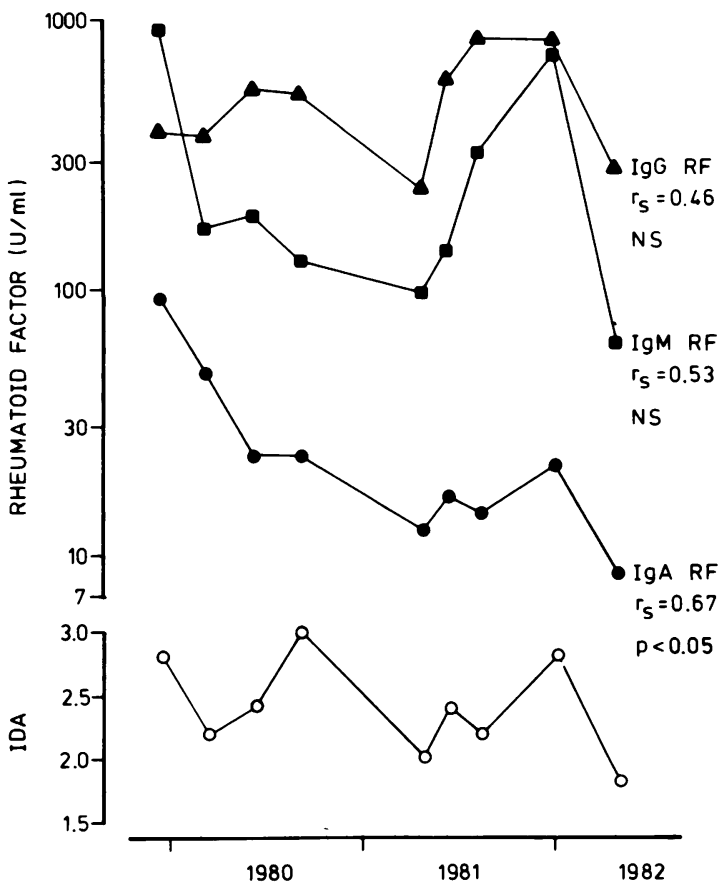

Fig. 1 The profiles of $\operatorname{Ig} M R F, \operatorname{Ig} A R F, \operatorname{Ig} G R F$, and the index of disease activity (IDA) for one patient from nine successive assessments during 1979-82. Spearman's rank correlation coefficients $\left(r_{s}\right)$ for the association between IDA and the RF profiles are shown. 
association between the fluctuations in the IDA and the IgA RF was statistically significant $\left(r_{s}=0.67\right.$, $\mathrm{p}<0 \cdot 05$ ).

Fig. 2 shows the distribution in the group of 33 of the normalised Spearman's rank correlation coefficients $\left(r_{s} \sqrt{n-1}\right)$ for the association between IDA and IgA RF, IgM RF, and IgG RF, respectively. Although the scatter was considerable, the mean $r_{s} \sqrt{n-1}$ value for the association between IDA and IgA Rf was significantly positive (a mean of 0.497 (SD 1.023), $<<0.02$, Student's $t$ test), implying an overall positive association in the group between fluctuations in $\operatorname{IgA}$ RF and disease activity during the follow-up. There was no such overall significant association, however, between fluctuations in IgM RF or IgG RF and IDA (Fig. 2).

Table 3 shows the summarised results of a similar analysis where the within-patient association of fluctuations in EMS, PVAS, RAI, GS, ESR, IgA RF, and IgM RF for the group of 33 was studied. The table shows the mean \pm SD of the $r_{s} \sqrt{n-1}$ values and the significance of the deviation from zero of the mean $r_{s} \sqrt{n-1}$. The fluctuations of the different clinical parameters for each patient were closely associated. For example, the interrelation of PVAS and RAI had a mean $r_{s} \sqrt{n-1}$ of $0.96 \pm 1.00$ $(t=5 \cdot 18, \mathrm{p}<0 \cdot 001$, Student's $t$ test). Similarly, the fluctuations of GS were closely associated with those of RAI and PVAS $(p<0 \cdot 001)$. The fluctuations in ESR closely followed those of GS (mean $r_{s} \vee n-1 \pm$ 1 SD of $-0.87 \pm 1 \cdot 11, p<0.001$ ). The fluctuations in ESR also showed a significant association with those of RAI $(0.55 \pm 1.07, \mathrm{p}<0.05)$ but there was no significant association between ESR and PVAS or EMS.

The fluctuations of the RF isotypes showed various interesting features. The fluctuation of $\operatorname{IgA}$ RF correlated closely with that of ESR $(0.57 \pm 0.96$, $\mathrm{p}<0.01)$, and there was also significant association between fluctuations in IgA RF and GS $(-0.41 \pm$ $1.02, \mathrm{p}<0.05)$, indicating that as GS deteriorated IgA RF tended to rise and vice versa.

The fluctuations of IgG RF also showed a significant correlation with those of ESR $(p<0 \cdot 02)$ and GS $(p<0 \cdot 05)$. However, there was no significant association between the fluctuations of IgG RF and IgA RF.

The fluctuations of IgM RF correlated significantly with those of IgA RF $(0 \cdot 60 \pm 1 \cdot 22, p<0 \cdot 01)$ and ESR $(p<0.05)$ but not with fluctuations of the clinical parameters (Table 3 ).

Table 3 shows that the total number of individuals behind each mean $r_{s} \sqrt{n-1}$ value was often less than 33. This was because no correlation coefficient could be calculated if a parameter remained constant throughout the observation period. For instance,

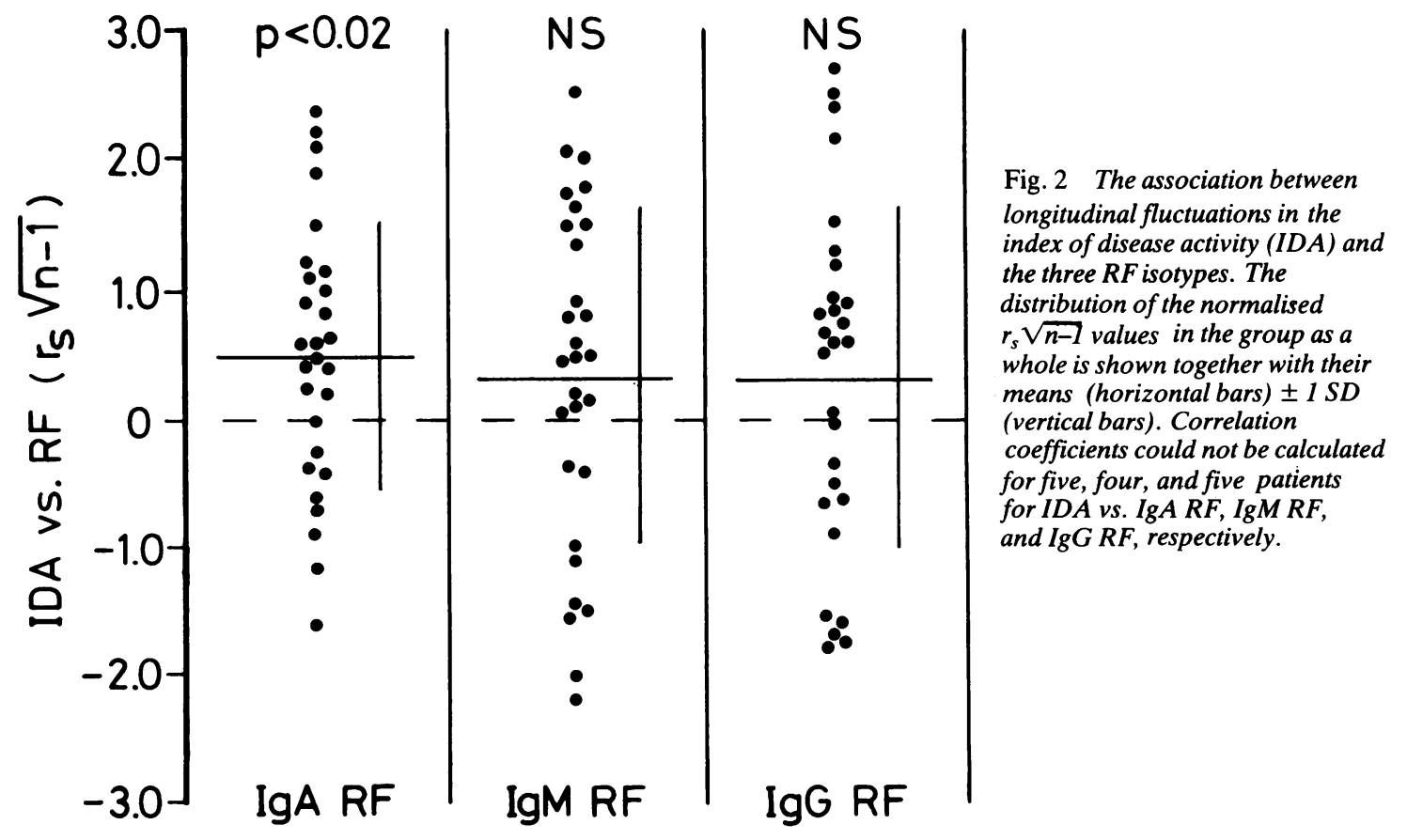

Fig. 2 The association between longitudinal fluctuations in the the three $R F$ isotypes. The distribution of the normalised $r_{s} \sqrt{n-1}$ values in the group as a whole is shown together with their means (horizontal bars) $\pm 1 S D$ (vertical bars). Correlation coefficients could not be calculated for five, four, and five patients for IDA vs. IgA RF, IgM RF, and IgG $R F$, respectively. 
Table 3 The relationship between longitudinal fluctuations in clinical parameters, ESR, and RFs during the follow-up of the group of 33

\begin{tabular}{|c|c|c|c|c|c|c|c|c|}
\hline & & $E M S$ & $P V A S$ & $R A I$ & $G S$ & $E S R$ & $\operatorname{Ig} A R F$ & $\lg G R F$ \\
\hline PVAS & $\begin{array}{l}\mathrm{n}^{*} \\
\bar{x} \pm 1 \mathrm{SD} \dagger \\
\mathrm{p}<\ddagger\end{array}$ & $\begin{array}{l}27 \\
0 \cdot 66 \pm 1 \cdot 22 \\
0 \cdot 01\end{array}$ & & & & & & \\
\hline RAI & $\begin{array}{l}\mathrm{n} \\
\overline{\mathrm{x}} \pm 1 \mathrm{SD} \\
\mathrm{p}<\end{array}$ & $\begin{array}{l}29 \\
0 \cdot 74 \pm 1 \cdot 14 \\
0 \cdot 01\end{array}$ & $\begin{array}{l}29 \\
0 \cdot 96 \pm 1 \cdot 00 \\
0 \cdot 001\end{array}$ & & & & & \\
\hline GS & $\begin{array}{l}\mathrm{n} \\
\overline{\mathrm{x}} \pm 1 \mathrm{SD} \\
\mathrm{p}<\end{array}$ & $\begin{array}{l}29 \\
-0 \cdot 56 \pm 0 \cdot 96 \\
0 \cdot 01\end{array}$ & $\begin{array}{l}30 \\
-0.65 \pm 0.95 \\
0.001\end{array}$ & $\begin{array}{l}31 \\
-0 \cdot 75 \pm 0.96 \\
0.001\end{array}$ & & & & \\
\hline ESR & $\begin{array}{l}\mathrm{n} \\
\overline{\mathrm{x}} \pm 1 \mathrm{SD} \\
\mathrm{p}<\end{array}$ & $\begin{array}{l}29 \\
0 \cdot 38 \pm 1 \cdot 04 \\
\text { NS }\end{array}$ & $\begin{array}{l}31 \\
0 \cdot 20 \pm 1 \cdot 07 \\
\text { NS }\end{array}$ & $\begin{array}{l}30 \\
0 \cdot 55 \pm 1 \cdot 26 \\
0 \cdot 05\end{array}$ & $\begin{array}{l}32 \\
-0 \cdot 87 \pm 1 \cdot 11 \\
0 \cdot 001\end{array}$ & & & \\
\hline IgA RF & $\begin{array}{l}\mathrm{n} \\
\overline{\mathrm{x}} \pm 1 \mathrm{SD} \\
\mathrm{p}<\end{array}$ & $\begin{array}{l}28 \\
0 \cdot 28 \pm 1 \cdot 04 \\
\text { NS }\end{array}$ & $\begin{array}{l}31 \\
0 \cdot 27 \pm 0 \cdot 94 \\
\text { NS }\end{array}$ & $\begin{array}{l}29 \\
-0.05 \pm 1 \cdot 14 \\
\text { NS }\end{array}$ & $\begin{array}{l}31 \\
-0.41 \pm 1 \cdot 02 \\
0.05\end{array}$ & $\begin{array}{l}32 \\
0 \cdot 57 \pm 0 \cdot 96 \\
0 \cdot 01\end{array}$ & & \\
\hline IgG RF & $\begin{array}{l}\mathrm{n} \\
\overline{\mathbf{x}} \pm 1 \mathrm{SD} \\
\mathrm{p}<\end{array}$ & $\begin{array}{l}28 \\
0 \cdot 33 \pm 1 \cdot 12 \\
\text { NS }\end{array}$ & $\begin{array}{l}28 \\
0 \cdot 25 \pm 1 \cdot 26 \\
\text { NS }\end{array}$ & $\begin{array}{l}30 \\
0 \cdot 24 \pm 1 \cdot 30 \\
\mathrm{NS}\end{array}$ & $\begin{array}{l}30 \\
-0 \cdot 50 \pm 1 \cdot 25 \\
0.05\end{array}$ & $\begin{array}{l}31 \\
0 \cdot 51 \pm 1 \cdot 12 \\
0 \cdot 02\end{array}$ & $\begin{array}{l}30 \\
0 \cdot 03 \pm 1 \cdot 13 \\
\text { NS }\end{array}$ & \\
\hline IgM RF & $\begin{array}{l}\mathrm{n} \\
\overline{\mathrm{x}} \pm 1 \mathrm{SD} \\
\mathrm{p}<\end{array}$ & $\begin{array}{l}29 \\
0 \cdot 33 \pm 1 \cdot 08 \\
\text { NS }\end{array}$ & $\begin{array}{l}30 \\
0 \cdot 04 \pm 1 \cdot 24 \\
\text { NS }\end{array}$ & $\begin{array}{l}31 \\
0 \cdot 03 \pm 1 \cdot 16 \\
\text { NS }\end{array}$ & $\begin{array}{l}32 \\
-0 \cdot 09 \pm 1 \cdot 22 \\
\text { NS }\end{array}$ & $\begin{array}{l}33 \\
0 \cdot 42 \pm 1 \cdot 18 \\
0 \cdot 05\end{array}$ & $\begin{array}{l}32 \\
0 \cdot 60 \pm 1 \cdot 22 \\
0 \cdot 01\end{array}$ & $\begin{array}{l}31 \\
0 \cdot 20 \pm 1 \cdot 08 \\
\text { NS }\end{array}$ \\
\hline
\end{tabular}

${ }^{*}$ The number of patients $(<33)$ for whom Spearman's rank correlation coefficients $\left(r_{\mathrm{s}}\right)$ could be calculated.

$\dagger$ The mean and standard deviation of the normalised rank coefficients $\left(r_{s} \sqrt{n-1}\right)$.

$\ddagger$ The significance of the deviation of $\overline{\mathrm{x}}$ from zero as assessed by the Student's $t$ test.

four patients never had any early morning stiffness during the study. Consequently, the number behind each $r_{s} \sqrt{n-1}$ involving EMS never exceeded 29.

The relationship between the correlation coefficients $\left(r_{s}\right)$ for parameters $X$ vs. Y and the absolute values of $\mathrm{X}$ and $\mathrm{Y}$ during the study period was examined by a multivariate correlation analysis, employing Spearman's rank correlation method. The strength of the association was generally not related to the initial, mean, or maximal values of the parameters involved during the study period. For example, there was no significant correlation between the $r_{s} \sqrt{n-1}$ values for the association between IgA RF and IDA and the initial IgA RF values.

\section{Discussion}

The natural course of RA is extremely variable, from one brief attack of synovitis which may barely meet conventional criteria for definite RA to severe, destructive relentlessly progressive disease. It may therefore be expected that those patients who continue to attend a long-term follow-up clinic are preferentially those with the more severe disease. Indeed, some of those eight who were lost to follow-up probably failed to attend because they remained free of symptoms.
It is well established that the between-observer variation in assessments like the Ritchie articular index (RAI) is unacceptably high. ${ }^{11}$ As good technical reproducibility of the clinical and laboratory measures was of paramount importance in this study, the same physician carried out all the clinical assessments, and all the serum and synovial fluid samples for each patient were assayed for RFs (ELISA) on the same day. Furthermore, the clinic was always held at the same time of day (p.m.), thus reducing a possible diurnal variation.

$61 \%(17 / 28)$ of our RA patients developed erosive disease of their hands and wrists during the followup. That broadly agrees with Brook and Corbett, ${ }^{19}$ who found $43 \%(40 / 94)$ prevalence of 'diagnostic' hand erosions after two years. As the range of the length of follow-up was relatively short (24-48 months), we felt justified in using the unmodified hand and wrist erosion count as a measure of the outcome. $^{10}$

The frequency of seropositivity in RA as judged by the sheep cell agglutination test is often quoted as being at least $75 \% .{ }^{1}$ Consequently the frequency of RAHA seropositivity in our group $(39 \%$ of the whole group, $46 \%$ of the RA patients) may seem rather low. However, other authors have also noted 
low frequency of seropositivity in prospective studies of early RA. Masi et al. ${ }^{20}$ studied 50 young adult RA patients, 38 of whom developed classical/ definite RA, and found that only $44 \%(22 / 50)$ ever became seropositive. Our finding that only few patients developed raised RF level (ELISA) during the follow-up also agrees with the findings of Masi et $a l .,{ }^{20}$ as only two of their 50 patients became seropositive subsequent to the entry.

Several authors have attempted to correlate serum levels of rheumatoid factors and immune complexes with clinical features. ${ }^{21-23}$ However, these calculations have mostly been based on cross-sectional analyses which fail to take into account individual differences in the baseline of parameters like, for example, the grip strength. Longitudinal within-patient studies would therefore seem more appropriate for the assessment of a possible relationship between for example RF levels and clinical indices of disease activity.

Our finding that, of the three RF isotypes studied, IgA RF showed the closest association in fluctuations in disease activity may seem unexpected. The data in Table 3 suggest that IgA RF may behave like an acute phase reactant. However, fluctuations in IgG RF also showed a significant association with both ESR and GS. It was interesting that, even in patients with normal RFs, the RF fluctuations sometimes showed a significant association with fluctuations of the clinical parameters. These observations further strengthen our finding that the measurement of IgA RF may yield important information in RA, ${ }^{10}$ as we showed that raised IgA RF in early RA was significantly associated with the later development of erosive disease, whereas neither IgM RF nor IgG RF were.

The possible relation of IgA RF to disease activity and severity in RA has received limited attention, perhaps because IgA is a poor activator of complement and phagocytes and would therefore seem unlikely to be directly involved in the pathogenesis of RA. Marcolongo et al. ${ }^{24}$ reported that total serum. IgA was raised in most RA patients but raised total serum IgG was found only in seropositive RA. However, these workers did not find any relationship between the immunoglobulin levels and the course or duration of disease. Furthermore, treatment of RA with gold or penicillamine may precipitate IgA deficiency, ${ }^{25}$ though the mechanisms are unclear.

Recently an interesting relationship between $\operatorname{IgA}$ and the HLA-B27 associated arthropathies has been reported. Ebringer ${ }^{26}$ showed that serum IgA levels in 122 ankylosing spondylitis (AS) patients were significantly related to their ESR and Wright $e t$ $a{ }^{27}$ suggested that IgA may behave like an acute phase reactant in patients with AS. Granfors et al. ${ }^{28}$ furthermore showed that the persistence of $\operatorname{IgA}$ anti-yersinia antibodies was directly related to the development of arthritis following yersinia infection, and Panayi $^{29}$ reported that serum antiklebsiella $\operatorname{IgA}$ antibodies were significantly higher in patients with active AS than in patients with inactive AS, psoriatic arthritis, or RA.

Lessard et al. ${ }^{22}$ recently reported that, whereas IgG RF levels correlated both with articular index on one occasion and changes in articular index with time, IgA RF failed to show such a correlation. However, this was a cross-sectional study with only a few observations on each patient and over a relatively short period of time (a mean of 8.5 months).

It is not clear why IgA RF should be more closely associated with fluctuations in disease activity than the other RF isotypes. Perhaps a flare-up of RA is normally accompanied by polyisotypic RF production of which the IgG RF and IgM RF contribute to the inflammatory reaction by activation of complement and phagocytes. This in turn may lead to rapid clearance and turnover of $\mathrm{IgG} \mathrm{RF}$ and $\mathrm{IgM} \mathrm{RF}$ in the joints and only a limited spillover into the peripheral circulation. IgA RF, however, being ineffective at activating complement and phagocytes, might persist longer in the body and thus serve as an easily detectable marker for disease activity in rheumatoid arthritis.

The authors are most grateful to $\mathrm{Nr} \mathbf{R}$. F. Galbraith, Department of Statistical Sciences, University College, London, for his expert statistical advice on the data analysis. We also acknowledge the invaluable technical help of Miss D. Beaumont, the Computer Unit, St Mary's Hospital Medical School, with the computer analysis.

This work was supported by grants from the Icelandic Science Foundation, Astra-Sytex Scandinavia Ltd, and NATO. I.T. was in receipt of a British Council scholarship for 14 months during the course of this work.

\section{References}

1 Fye $\mathrm{K} \mathrm{H}$, Moutsopoulos $\mathrm{H} \mathrm{M}$, Talal N. In: Fudenberg $\mathrm{H} \mathrm{H}$, Stites D P, Caldwell J L, Wells J V, eds. Basic and clinical immunology. 2nd ed. Los Altos, California: Langc, 1978; 422-51.

2 Munthe E, Natvig J B. Immunoglobulin classes, subclasses and complexes of IgG rheumatoid factor in rheumatoid plasma cells. Clin Exp Immunol 1972; 12: 55-70.

3 Winchester R J, Agnallo V, Kunkel H G. Gamma globulin complexes in synovial fluids of patients with rheumatoid arthritis. Partial characterisation and relationship to lowered complement levels. Clin Exp Immunol 1970; 6: 689-706.

4 Male D, Roitt I M, Hay F C. Analysis of immune complexes in synovial effusions of patients with rheumatoid arthritis. Clin Exp Immunol 1980; 39: 297-306.

5 Otten H A, Boerma F W. Significance of the Waaler-Rose test streptococcal agglutination, and antistreptolysin titre in the prognosis of rheumatoid arthritis. Ann Rheum Dis 1959; 18: 24-8. 
6 Kunkel H G, Muller-Eberhard H J, Fudenberg H H, Tomasi T B. Gamma globulin complexes in rheumatoid arthritis and certain other conditions. J Clin Invest 1961; 40: 117-29.

7 Heimer R. Levin F M. On the distribution of rheumatoid factors among the immunoglobulins. Immunochemistry 1966; 3: $1-10$.

8 Carson D A, Lawrence S, Catalano $\mathrm{M} \mathrm{A}$, Vaughan $\mathbf{J} \mathbf{H}$, Abraham G. Radioimmunoassay of IgG and IgM rheumatoid factors reacting with human IgG. J Immunol 1977; 119: 295-300.

9 Dunne J V. Carson D A. Spiegelberg H L. Alspaugh M A. Vaughan J H. IgA rheumatoid factor in the sera and saliva of patients with rheumatoid arthritis and Sjögren's syndrome. Ann Rheum Dis 1979; 38: 161-5.

10 Teitsson I, Withrington R H, Seifert M H, Valdimarsson $\mathrm{H}$. Prospective study of early rheumatoid arthritis. I. Prognostic value of $\operatorname{IgA}$ rheumatoid factor. Ann Rheum Dis.

11 Ritchie D M. Boyle J A. McInnes J M, et al. Clinical studies with an articular index for the assessment of joint tenderness in patients with rheumatoid arthritis. $Q J$ Med 1968; 37: 393-406.

12 Savage O. Measurements in rheumatoid arthritis. Proc $R$ Soc Med 1966; 59 (suppl): 85-8.

13 Teitsson 1. Antiglobulins in relation to rheumatic diseases: Development of ELISA assays and their application in prospective and family surveys. London: University of London, 1983. $\mathrm{PhD}$ thesis.

14 Ropes M W, Bennett G A. Cobb S. Jacox R. Jessar R A. 1958 revision of diagnostic criteria for rheumatoid arthritis. Bull Rheum Dis 1958; 9: 175-6.

15 Mallya R K, Mace B E W. The assessment of disease activity in rheumatoid arthritis, using a multivariate analysis. Rheumatol Rehabil 1981; 20: 14-7.

16 Dixon W J, Brown M B, eds. Biomedical computer programs, P-series, Berkeley, California: University of California Press, 1979.

17 Finnie A, Mason M, Muir C. Evaluation of the RAHA test for rheumatoid factor. Med Lab Technol 1974; 31: 323-6.

18 Withrington R H, Teitsson I, Seifert M H, Valdimarsson H. Felty's syndrome associated with high levels of IgA rheumatoid factor. Ann Rheum Dis 1984; 43: 505-7.
19 Brook A. Corbett M. Radiographic changes in early rheumatoid disease. Ann Rheum Dis 1977; 36: 71-3.

20 Masi A T, Maldonado-Cocco J A. Kaplan S B, Feigenbaum S L, Chandler R W. Prospective study of the early course of rheumatoid arthritis in young adults: comparison of patients with and without rheumatoid factor positivity at entry and identification of variables correlating with outcome. Semin Arthritis Rheum 1976: 5: 299-326.

21 Wernick R, Merryman P. Jaffe I, Ziff M. IgG and IgM rheumatoid factors in rheumatoid arthritis. Quantitative response to penicillamine therapy and relationship to disease activity. Arthritis Rheum 1983; 26: 593-8.

22 Lessard J. Nunnery E, Cecere F, McDuffy S, Pope R M. Relationship between the articular manifestations of rheumatoid arthritis and circulating immune complexes detected by three methods and specific classes of rheumatoid factors. $J$ Rheumatol 1983; 10: 411-7.

23 Ogrino M A. Robbins D, Alspaugh M. Association of IgG-rheumatoid factor, IgM-rheumatoid factor, antirheumatoid arthritis-associated nuclear antigen levels with disease activity in rheumatoid arthritis patients. Arthritis Rheum 1983; 26 (suppl): s 50.

24 Marcolongo R Jr, Carcassi A. Frullini F, Bianco G, Bravi A. Levels of serum immunoglobulins in patients with rheumatoid arthritis. Ann Rheum Dis 1967; 26: 412-8.

25 Johns P, Felix-Davies D D. Hawkins C F, et al. IgA deficiency in patients with rheumatoid arthritis treated with Dpenicillamine or gold. Ann Rheum Dis 1978; 37: 289.

26 Ebringer A. The cross tolerance hypothesis. HLA-B27 and ankylosing spondylitis. $\mathrm{Br} J$ Rheumatol 1983; 22 (suppl 2): 53-66.

27 Wright V, Neumann V, Shinebaum R, Cooke E M. Pathogenesis of seronegative arthritis. BrJ Rheumatol 1983; 22 (suppl 2): 29-32.

28 Granfors K, Viljanen M. Tiililainen A. Toivenan A. Persistence of IgM, IgG and IgA antibodies to yersinia in yersinia arthritis. J Infect Dis 1980; 141: 424-9.

29 Panayi G S. ELISA studies in ankylosing sponylitis. $\mathrm{Br} J$ Rheumatol 1983; 22 (suppl 2): 119-21. 